The Separate and Joint Influence of Teammate and Opponent Skill on Player Skill Development

\author{
Yidan Liu \\ Department of Psychology, The University of Sheffield \\ yliu376@sheffield.ac.uk
}




\begin{abstract}
Individuals constantly interact with and are affected by environments. In the context of team-based online video games, of particular interest is whether players are affected by their peers - teammates and opponents. In this article, I present a large-scale study on the effect of inter-player skill gap on skill learning. A dataset from an online game, Conquer Club, is used to describe changes in skill of players interacting with teammates and opponents of varying skill levels. Linear and nonlinear regression analyses have been performed to understand the separate and joint influence of teammates and opponents skill. Results confirm the importance of opponents' skill levels with respect to players' skill development, and show that competing against higher level opponents is beneficial to skill increments. But this study fails to conclude if players' changes in skill are influenced by teammates' skill and are moderated jointly by teammates and opponents' skill. Additionally, there is a nonlinear relationship between skill improvements and pregame skill. Reasons for these results are discussed at the end.
\end{abstract}

Keywords: online game, skill acquisition, teammates, opponents 


\section{The Separate and Joint Influence of Teammate and Opponent Skill on Player Skill Development}

You would often hear claims from the experts (commentators and athletes) that if you have one good team (exceeds expectations) in a generally low performing league, that means that the league can improve and become better. In essence, the performance of the complete league can be pulled up by one overperforming team.

-Nemanja Vaci mentioned effects of environments in email (2020)

\section{Environmental effects}

A considerable amount of literature has highlighted the importance of environmental factors (e.g., the presence of peers, Zimmer \& Toma, 2000; organisational culture, Martins \& Terblanche, 2003; interindividual influences, de Bruijn, Kremers, de Vries, van Mechelen, \& Brug, 2006) to outcomes of individuals (e.g., educational achievements, Hanushek, Kain, Markman, \& Rivkin, 2003; job performance, Becker \& Klimoski, 1989; healthy behaviours, Brug, Kremers, Lenthe, Ball, \& Crawford, 2008).

Likewise, the team itself is also an environment that has a great impact on learning and performance of individuals in multiple fields. Involving in teams helps students achieve better academic performance and improves their learning (Abdelkhalek, Hussein, Gibbs, \& Hamdy, 2010). Team environments are also associated with athletes' performance (Carron, Colman, Wheeler, \& Stevens, 2002). In the context of video games, more team games played is associated with players' long-run skill development (Landfried, Fernández Slezak, \& Mocskos, 2019).

Teammates and opponents are the core of team environments, however, individual-level outcomes likely influenced by them receive less attention. As a case in point, only one meta-analysis explicitly focuses on the relationships between demographic and psychological attributes of team members and individual work-related outcomes (Guillaume, Brodbeck, \& Riketta, 2012). In contrast, most studies of team members emphasise their impact on team-level outcomes. For instance, a considerable amount of literature has explored relations among (e.g., personal relationships; Hinds, Carley, Krackhardt, \& Wholey, 2000; prior shared success; Mukherjee, Huang, Neidhardt, Uzzi, \& Contractor, 2019) and characteristics of (e.g., 
demographic variable, see Bell, Villado, Lukasik, Belau, \& Briggs, 2011 for a meta-analytic review; psychological variable, see Bell, 2007 for a meta-analytic review; skill level; Swaab, Schaerer, Anicich, Ronay, \& Galinsky, 2014) team members as predictors of team performance.

\section{Skill acquisition}

This study focuses on individual-level performance, which could be measured by many metrics, and in this article it is reflected by skill acquisition. It is well established from a variety of studies that practice quantity significantly influences skill acquisition; individuals become skilled with practice while the speedup proceeds at an overall decreasing rate (i.e. the power law of practice; Newell \& Rosenbloom, 1981; or the exponential law of practice; Heathcote, Brown, \& Mewhort, 2000; or the delayed random exponential law of practice; Evans, Brown, Mewhort, \& Heathcote, 2018). Importantly, the quality of practice also plays a role in skill acquisition. Here, I am interested in whether interactions with different skill levels of teammates and opponents are of different quality which influence one's skill acquisition, which has not been adequately studied.

\section{The current study}

Leveraged from knowledge relevant to peer effects, it may be speculated that peers within a team (i.e. teammates) and peers in the opposition team (i.e. opponents) would affect individual skill acquisition.

Teammate's influence. It has long been observed that individuals' performance might be influenced by their peers (Falk \& Ichino, 2006; Triplett, 1898). But research findings vary widely and as such, it is hard to decide how to group individuals with different skill levels across various conditions (Epple \& Romano, 2011). In educational and organisational settings, some research fails to conclude positive effects of high-ability individuals to low-ability ones (e.g., Carrell, Sacerdote, \& West, 2013), while there is also research supporting that high-productivity individuals will increase performance of their peers (e.g., Li, Han, Zhang, \& Rozelle, 2014; Mas \& Moretti, 2009). A possible mechanism underlying the positive effects of high-level peers is social learning caused by observations of and interactions with high-level peers (Bursztyn, Ederer, Ferman, Yuchtman, 2014). Likewise, it may be inferred that individual players could improve their skill through imitation of higher-level teammates in team-based games. 
Opponent's influence. The notion of desirable difficulties suggests that introducing some difficulties might lead to better skill learning (Bjork, 1994). Previous research has established that in sports contexts, competing against higher-level opponents relates to more effort and inputs, such as increased high-intensity activities (Rampinini, Coutts, Castagna, Sassi, \& Impellizzeri, 2007) and time-motion demands (Folgado, Duarte, Fernandes, \& Sampaio, 2014) in matches. Accordingly, to overcome higher-level opponents in a competition could be regarded as a kind of difficulty. There is a study supporting that a swimmer could perform better when their competitors were faster (Jane, 2015). But some research believes that the presence of super highly-skilled players is associated with lower performance of their competitors (e.g., Brown, 2011). Taken together, with respect to impact of opponents, it perhaps could be predicted that competing against slightly higher-level opponents is a desirably challenging task to facilitate long-run skill development of players.

Predictions. The present body of evidence indicates potential relevance between skill development of players and skill levels of their teammates and opponents. Nevertheless, very little is currently known about whether and how skill levels of teammates and opponents as well as their interaction influence an individual's learning rate. In this study, the separate and joint influence of teammates' skill and opponents' skill on the player's learning efficiency was examined. It was hypothesised that skill acquisition of the online video gamer would follow 'the law of practice' (Newell \& Rosenbloom, 1981), that is, they become skilled with practice but improvement decreases at the same time. And such learning rate would be moderated by the joint influence of skill levels of teammates and opponents. It was also hypothesised that they would benefit from cooperating with higher level teammates or competing against slightly higher level opponents.

Game. Previous research has demonstrated that online games are a great platform to collect a large amount of behavioural information in natural settings to study skill learning (e.g., Stafford \& Dewar, 2014). The present work is feasible owing to the accessibility of open-source data which is about an online strategy game, Conquer Club. This platform is ideal for studying effects of skill composition for the following reasons. First, players can freely join open team games and battle with other teams. Given that there are no matching mechanisms in the game, it is possible to collaborate with and challenge players of different skill levels. Second, there is a popular method TrueSkill (Herbrich, Minka, \& Graepel, 2007) estimating a player's skill, a 
hidden variable which cannot totally be reflected by scores. This method has been used to identify and track players' skill in Conquer Club by Landfried et al. (2019), who studied impacts of team play strategies in skill acquisition. In their dataset, players' skill has been calculated and recorded. Third, the access to the corresponding data from $2006 / 01 / 03$ to $2009 / 07 / 12$ is available, including about 4.4 million games played by 0.27 million players. This rich data not only records real player skill changes but also offers greater statistical power than laboratory experiments. The above-mentioned hypotheses of this study will be tested using the published data in Landfried et al. (2019).

Purpose. The aim of this study is to examine relationships between changes in skill of players and a) pregame skill of themselves; b) skill levels of their teammates; c) skill levels of their opponents; and d) skill levels of teammates and opponents. The primary motivation for this study is to understand changes in skill in different situations and further, to provide insights on self-improvement and training optimisation. Basically, players desire to improve their skill, especially in a team environment. It is believed that individual performance is crucial to a team's performance (Chen, Kirkman, Kanfer, Allen, \& Rosen, 2007) and it is commonly held that more talented individuals of a team are beneficial to team success (Gula, Vaci, Alexandrowicz, \& Bilalic, 2020; Swaab et al., 2014). This study may suggest players to enhance skill in a more efficient way via choosing suitable teammates and opponents. And coaches could design and assemble different team compositions of different skills to train players to address skill deficiencies and optimise their abilities.

The article has been organised in the following way. First, the main analysis in the research of Landfried et al. (2019) using the original dataset is replicated. It will then go on to describe the deprived data used for the current study and preliminary processing of data. Next, the basic phenomenon of skill learning rate of players changing with their initial skill will be investigated. Followed by performing analyses to address research questions and presenting results focusing on the separate and joint influence of skill levels of teammates and opponents on individual skill changes. At the end of this article, general discussion is presented. 


\section{Analysis}

\section{Analysis Plan}

Regression analysis. This study attempts to analyse how initial skill level of oneself, teammate skill level, opponent skill level and their interactions influence one's skill learning in an online game. In essence, the questions can be seen as estimating the relationships between the dependent variable (i.e. individual skill changes after a game) and independent variables (i.e. pregame skill level, teammates' skill, opponents' skill, and the interaction between teammates and opponents), which directly boil down to the classic regression analysis. I will first conduct the most basic form of regression analysis, namely the linear regression, to test if correlations of variables are approximately linear, as well as to observe the overall trends. In addition, to better depict complexity of the real world, i.e., nonlinear relationships are more common, I will further perform polynomial regression analysis as an alternative strategy. The goodness of fit for regression models will be compared to determine the most promising ones. The analysis plan was pre-registered at https://osf.io/qs2mp. The analysis was approved by the Department of Psychology Ethics Sub-Committee at the University of Sheffield.

Robust method. The least-squares is the most popular metric utilised to estimate regression parameters. However, it has been demonstrated that least squares become vulnerable when outliers exist (Hampel, Ronchetti, Rousseeuw, \& Stahel, 1986). To overcome this shortcoming, some methods which are less sensitive to noise, namely robust estimations, have been proposed. Based on the idea of maximising likelihood estimation, Huber (1964) invited the M-estimator which extends the workflow of least squares by taking an iterative approach to reweigh regression parameters. Empirical results show that M-estimator is very robust against outliers and should be recommended as an effective tool to perform regressions on noisy data (Hampel et al., 1986). In this study I select regression with M-estimator as my data analysis approach, since the research data exhibits severe long-tail issues (cf. Figure 3). However, the available APIs do not provide the functions for calculating goodness-of-fit scores (e.g., R-squared) for the robust model. Inspired 
by an unmerged pull request ${ }^{1}$ for the main branch of the statsmodels GitHub repository, I successfully reimplemented the R-squared algorithm for robust testing in the book of Hampel et al. (1986, Chapter 7) by decoupling the original code. To guarantee the replicability of my work as well as to aid future research, all code for this project has been released under the MIT License. Interested readers could find them at https://github.com/yidanliu-psy/final project.

Reproduction. The data used in this study is that of Landfried et al. (2019). In order to have a more thorough understanding of their data, before conducting novel processing steps to investigate my research question, I first reproduce the main analysis reported in their original paper. To begin with, data including players information such as player id, player skill and game type is extracted. Next, following the procedure in their article, only players with no less than 4 team games played are included in the analysis. In the replication, the faithfulness-boost effect they discovered, i.e., "playing loyally with the same teammate significantly accelerates short-run skill acquisition" (Landfried et al., 2019, p.1), has been successfully observed and confirmed. The overall patterns coincide well, though there are several slight discrepancies between detailed results which might be due to numerical or calculation variations. In the results of Landfried et al. (2019), faithfulness effect is significant until 400 games played (Figure 1), while in the reproduction output, the effect contributes to skill acquisition until 600 games played (Figure 2). 


\section{Figure 1}

Original: faithfulness effect copied from Landfried et al. (2019)

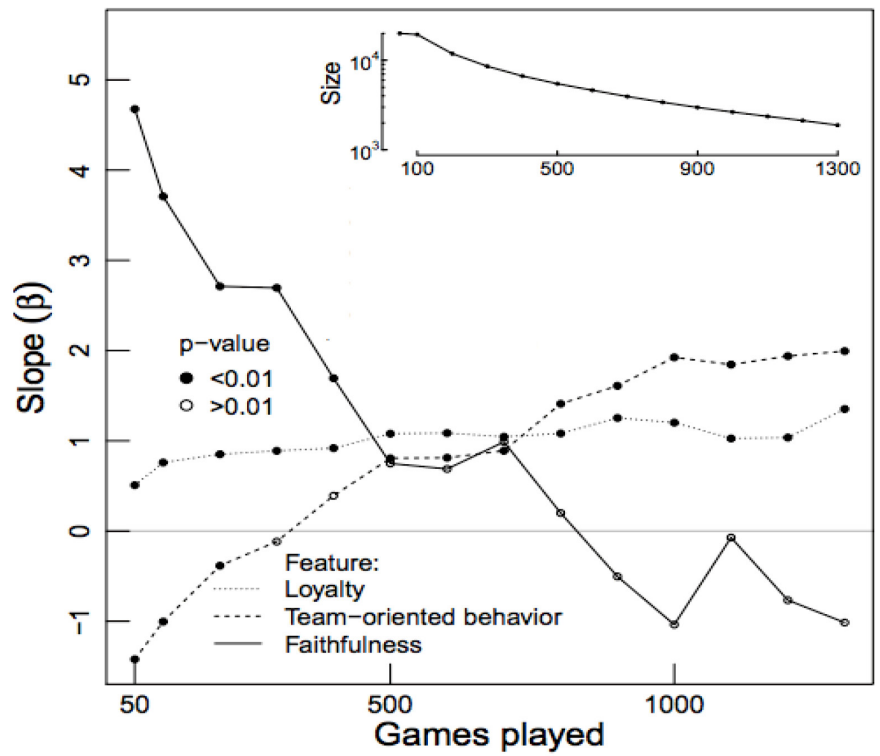

Note. Influence of faithfulness interaction over players skill acquisition ceases to be significant after 400 games played. The subplot shows the population size at each point of experience.

\section{Figure 2}

Reproduction: faithfulness effect following Landfried et al. (2019)

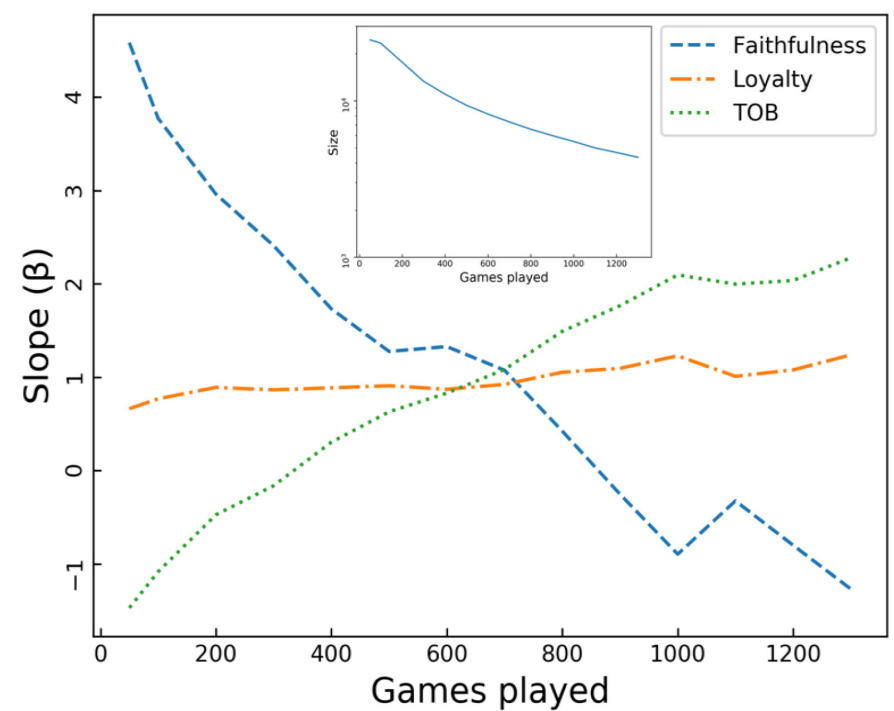

Note. Influence of faithfulness interaction over players skill acquisition ceases to be significant after 600 games played. The subplot shows the population size at each point of experience. 


\section{Code and Data}

As stated in the previous section, players' skill has already been calculated based on the TrueSkill toolkit in the dataset released by Landfried et al. (2019). To retrieve the core variables for the regression analysis, I first do some pre-processing: The first step is to identify team games, which is accomplished by cross-referring to the "game" table. In this study, a team game refers to a match with two teams regardless of the number of players in each team. Therefore, those games with more than two teams are excluded. Then, I calculate the ratio of averaged teammates skill to individual skill $(T / I)$ and the ratio of averaged opponents skill to individual skill $(\mathrm{O} / \mathrm{I})$, which are taken as independent variables. The pregame individual skill (I) is also recorded. The dependent variable - individual skill changes $(\Delta)$ is defined as skill increments after a game. As the result, the output data is formatted as a matrix with four rows, which correspond to $\Delta, \mathrm{I}, \mathrm{T} / \mathrm{I}$ and $\mathrm{O} / \mathrm{I}$, respectively. It serves as the basis for all subsequent analyses.

\section{Preliminary Analysis: Preparatory Work}

A large amount of data is included in this study (Table 1), and see Table 2 for the descriptive statistics of all data. The frequency density of variables involved in the analysis is presented in Figure 3.

\section{Table 1}

Observations in each team game type

\begin{tabular}{lc}
\hline Team game type & Player times (observations) \\
\hline 2 vs. 2 & $1,724,116$ \\
3 vs. 3 & $1,217,904$ \\
4 vs. 4 & 666,224 \\
All & $3,608,244$ \\
\hline
\end{tabular}

Table 2

Summary statistics of all data

\begin{tabular}{lcccc}
\hline Variable & Min. & Max. & Mean & Std. Error \\
\hline $\mathrm{I}$ & 4.41 & 58.52 & 30.18 & 2.66 \\
$\mathrm{~T} / \mathrm{I}$ & 0.15 & 6.53 & 1.00 & 0.09 \\
$\mathrm{O} / \mathrm{I}$ & 0.40 & 7.33 & 1.00 & 0.12 \\
$\Delta$ & -12.47 & 12.48 & 0.01 & 0.45 \\
\hline
\end{tabular}




\section{Figure 3}

Frequency density of variables
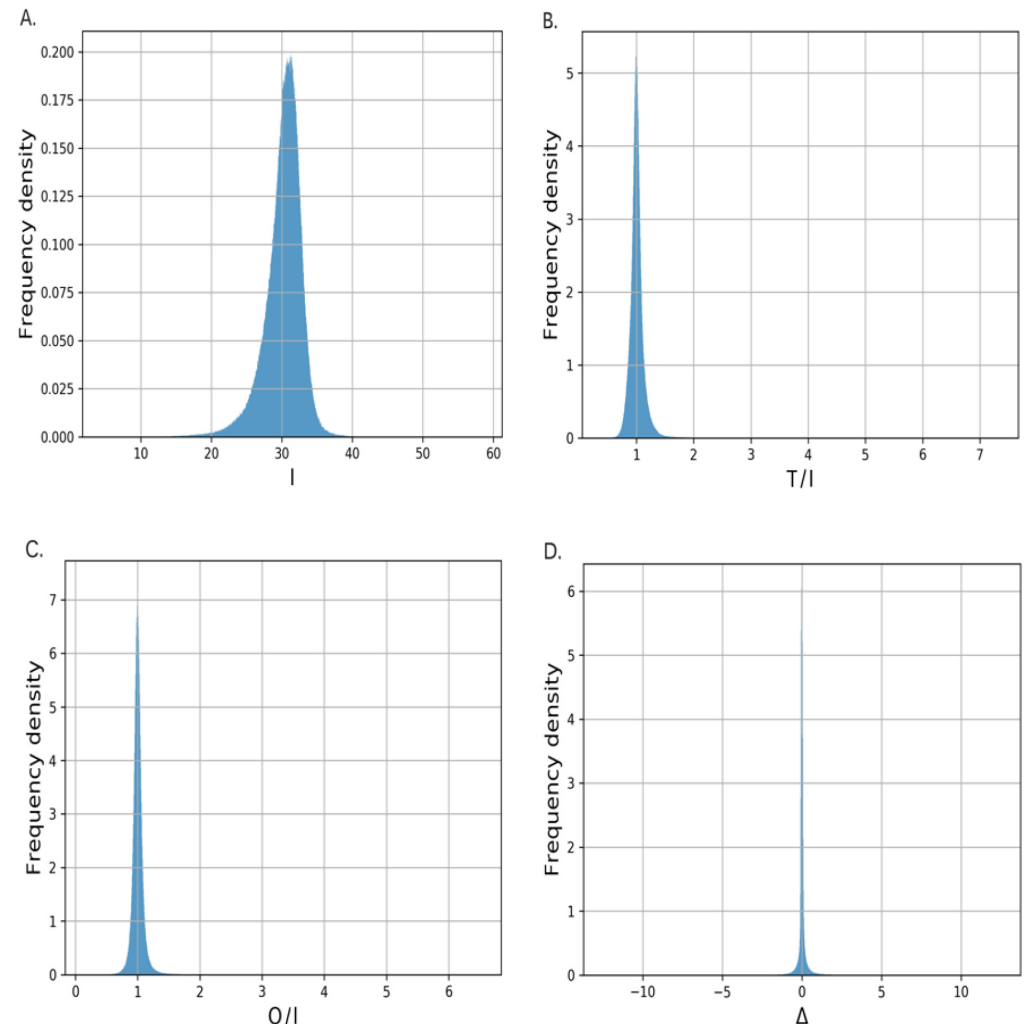

The basic phenomenon

As a fundamental question, whether changes in skill decrease with rising pregame skill is investigated in the first place. Correlations between players' changes in skill and their pregame skill in three team games are calculated (Table 3). The correlation is weak but significant; players' skill increment after a game is negatively correlated with their skill before a game. To infer a causal interpretation

Table 3

Spearman correlation coefficient (r) between changes in skill and individual pregame skill

\begin{tabular}{lc}
\hline Team game type & $r$ \\
\hline 2 vs. 2 & $-0.17^{* * *}$ \\
3 vs. 3 & $-0.24^{* * *}$ \\
4 vs. 4 & $-0.21^{* * *}$ \\
All & $-0.20^{* * *}$ \\
\hline$* * p<.001$. &
\end{tabular}


of them, a linear and two nonlinear (quadratic and cubic polynomial) regression analyses are carried out. The quadratic polynomial model relatively has a better model fit compared with the linear one (more deviance of outcome explained), but improving the order to three only brings marginal enhancement (Table 4). Results

\section{Table 4}

Deviance explained (\%) in linear and nonlinear models

\begin{tabular}{lccc}
\hline $\begin{array}{c}\text { Team game } \\
\text { type }\end{array}$ & Linear model & $\begin{array}{c}\text { Second-order } \\
\text { nonlinear model }\end{array}$ & $\begin{array}{c}\text { Third-order } \\
\text { nonlinear model }\end{array}$ \\
\hline 2 vs. 2 & 2.43 & 3.08 & 3.22 \\
3 vs. 3 & 3.25 & 3.84 & 3.86 \\
4 vs. 4 & 2.69 & 2.94 & 2.95 \\
All & 2.56 & 3.07 & 3.16 \\
\hline
\end{tabular}

show that improvements decrease as individuals become skilled and turn to be slightly negative around initial skill of 30 but positively increase again when initial skill level reaches around 39 (see Table 5 and Figure 4). Besides, such patterns are observed in the three types of team games, but tend to be most evident in Double games when there are fewest players per team (i.e. two players in each team).

\section{Table 5}

Estimates of the quadratic function used to model changes in skill

\begin{tabular}{llll}
\hline $\begin{array}{c}\text { Team game } \\
\text { type }\end{array}$ & Intercept & Coef. (linear) & Coef. (quadratic) \\
\hline 2 vs. 2 & $2.438^{* * *}$ & $-0.139^{* * *}$ & $0.002^{* * *}$ \\
3 vs. 3 & $1.673^{* * *}$ & $-0.099^{* * *}$ & $0.001^{* * *}$ \\
4 vs. 4 & $0.724^{* * *}$ & $-0.041^{* * *}$ & $0.001^{* * *}$ \\
All & $1.690^{* * *}$ & $-0.099^{* * *}$ & $0.001^{* * *}$ \\
\hline
\end{tabular}

$* * * p<.001$. 


\section{Figure 4}

The effect of players pregame skill on their changes in skill

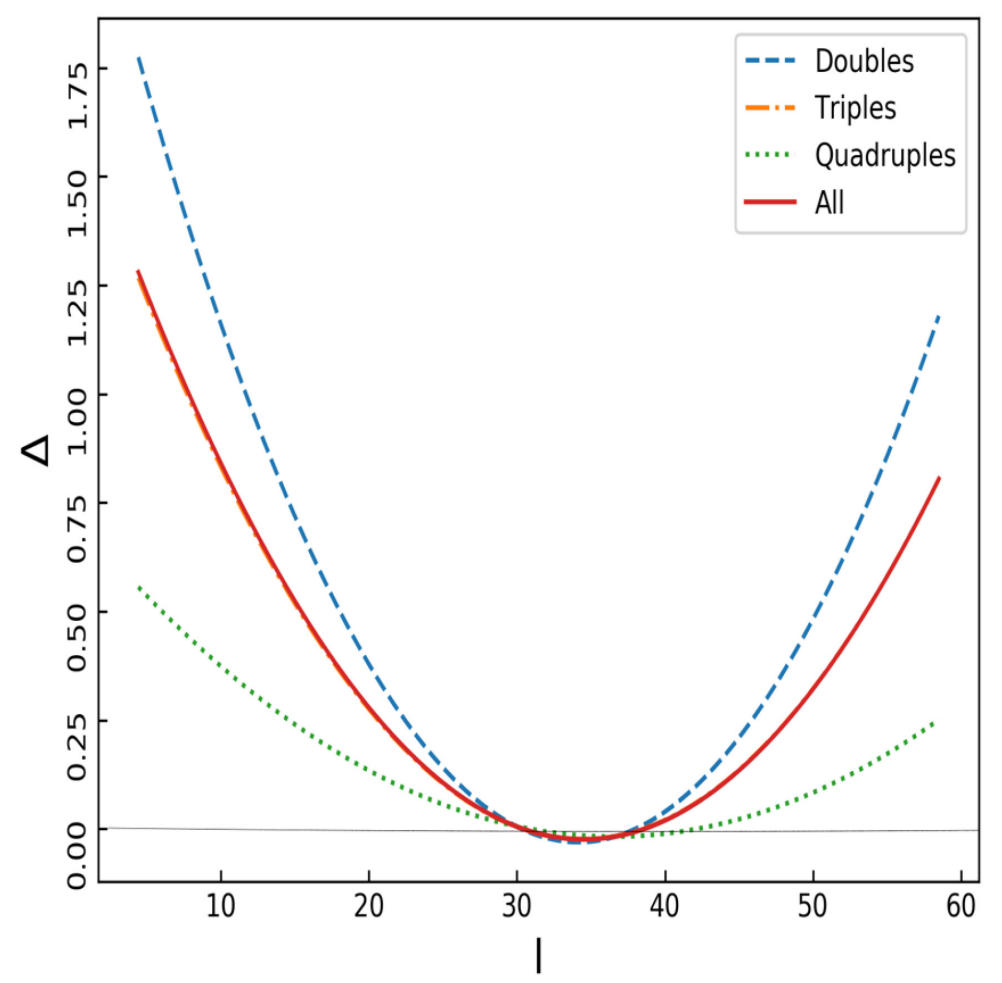

Note. The standard error of all regression slopes is less than 0.001 . The lines for

Triples and All almost overlap for their similar functions.

\section{Main analysis}

In this article, I focus on answering the following three main questions:

RQ1. Do players benefit from teaming up with higher level teammates?

RQ2. Do players benefit from competing against slightly higher level opponents?

RQ3. Do players' skill learning relate to skill composition of teammates AND opponents?

It should be noted that in this article, higher or lower level players are relative to the individual player's own level regardless whether they reach elite levels. For instance, player A with a level of 20 and player B with a level of 50 are both higher level players compared to player $\mathrm{C}$ with a level of 10 . Before carrying out regression analysis, whether there is collinearity between variables (i.e. T/I and O/I) has been checked via Variance Inflation Factor (VIF). All VIF in Doubles, Triples and Quadruples game types are less than 1.6, suggesting no evidence of 
collinearity.

Following the preregistration, a linear regression analysis has been performed to answer the above questions. In the preregistration, the relationship was investigated through building a model between individual skill changes and individual pregame skill, average skill of teammates, as well as average skill of opponents. However, this method ignores skill discrepancies between individuals and their teammates and opponents which may fail to illustrate the impacts of interacting with higher and lower skill players. Additionally, it is challenging to plot and present a four-dimensional graph with four variables. Therefore, a small departure from the preregistration has been made: To take skill discrepancies among players into account, independent variables are expressed in ratio, that is, average skill of teammates divided by individual skill $(\mathrm{T} / \mathrm{I})$, and average skill of opponents divided by individual skill $(\mathrm{O} / \mathrm{I})$. Linear interactions between individual skill changes $(\Delta)$ and these variables can be formalised as: $\Delta \sim \alpha \frac{T}{I}+\beta \frac{O}{I}$, similar to the formulation in the preregistration.

First, correlations between $\Delta$ and $\mathrm{T} / \mathrm{I}$ and $\mathrm{O} / \mathrm{I}$ in three team games are calculated (Table 6). Followed by fitting data into the model. The basic model starts

\section{Table 6}

Spearman correlation coefficient ( $r$ ) between variables

\begin{tabular}{lll}
\hline \multicolumn{1}{c}{ Team game type } & $r(\Delta-\mathrm{T} / \mathrm{I})$ & $r(\Delta-\mathrm{O} / \mathrm{I})$ \\
\hline 2 vs. 2 & $0.04^{* * *}$ & $0.26^{* * *}$ \\
3 vs. 3 & $0.04^{* * *}$ & $0.34^{* * *}$ \\
4 vs. 4 & $0.04^{* * *}$ & $0.27^{* * *}$ \\
All & $0.04^{* * *}$ & $0.29 * * *$ \\
\hline$* * * p .001$. & &
\end{tabular}

with $\mathrm{T} / \mathrm{I}$ and $\mathrm{O} / \mathrm{I}$ separately. Then both factors are added together. Finally, the interaction is added to the model. See Table 7 for models explaining skill development influenced separately and jointly by teammates and opponents. Unexpectedly, the ratio of teammates skill to individual skill contributes little to the model $(<1 \%)$, that is, teammates skill level could not predict individual skill changes in this study. As for $\mathrm{O} / \mathrm{I}$, it explains $3.51 \%$ of variance of changes in skill when all team games included. Owing to the little contribution 
of $T / I$, the explanation of data could hardly improve when both $T / I$ and $O / I$ are included in the model (compare $3.58 \%$ with $3.51 \%$ ). Similarly, adding the interaction to the model could not evidently increase explained variance (3.61\%; see also figure 6). Overall, $\mathrm{O} / \mathrm{I}$ positively predicts skill changes; the skill change is negative when players compete against opponents of lower level than themselves while it becomes positive increment when competing against higher level opponents (see Table 8 and figure 5).

\section{Table 7}

Models explaining changes in skill

\begin{tabular}{|c|c|c|}
\hline Team game type & Model & Deviance explained (\%) \\
\hline \multirow[t]{4}{*}{2 vs. 2} & $T / I$ & 0.17 \\
\hline & $0 / 1$ & 3.80 \\
\hline & $\mathrm{T} / \mathrm{I}+\mathrm{O} / \mathrm{I}$ & 3.89 \\
\hline & $\mathrm{T} / \mathrm{I}+\mathrm{O} / \mathrm{I}+\mathrm{T} / \mathrm{I} * \mathrm{O} / \mathrm{I}$ & 3.95 \\
\hline \multirow[t]{4}{*}{3 vs. 3} & $\mathrm{~T} / \mathrm{I}$ & 0.35 \\
\hline & $0 / 1$ & 4.14 \\
\hline & $\mathrm{T} / \mathrm{I}+\mathrm{O} / \mathrm{I}$ & 4.20 \\
\hline & $\mathrm{T} / \mathrm{I}+\mathrm{O} / \mathrm{I}+\mathrm{T} / \mathrm{I} * \mathrm{O} / \mathrm{I}$ & 4.23 \\
\hline \multirow[t]{4}{*}{4 vs. 4} & $\mathrm{~T} / \mathrm{I}$ & 0.39 \\
\hline & $0 / 1$ & 3.16 \\
\hline & $\mathrm{T} / \mathrm{I}+\mathrm{O} / \mathrm{I}$ & 3.19 \\
\hline & $\mathrm{T} / \mathrm{I}+\mathrm{O} / \mathrm{I}+\mathrm{T} / \mathrm{I} * \mathrm{O} / \mathrm{I}$ & 3.24 \\
\hline \multirow[t]{4}{*}{ All } & $\mathrm{T} / \mathrm{I}$ & 0.24 \\
\hline & $0 / 1$ & 3.51 \\
\hline & $\mathrm{T} / \mathrm{I}+\mathrm{O} / \mathrm{I}$ & 3.58 \\
\hline & $\mathrm{T} / \mathrm{I}+\mathrm{O} / \mathrm{I}+\mathrm{T} / \mathrm{I} * \mathrm{O} / \mathrm{I}$ & 3.61 \\
\hline
\end{tabular}

$* * * p<.001$. 
Table 8

Estimates of the linear function used to model changes in skill as $\mathrm{O} / \mathrm{I}$ increases

\begin{tabular}{lll}
\hline $\begin{array}{c}\text { Team game } \\
\text { type }\end{array}$ & Intercept & Coef. \\
\hline 2 vs. 2 & $-0.487^{* * *}$ & $0.491^{* * *}$ \\
3 vs. 3 & $-0.326^{* * *}$ & $0.335^{* * *}$ \\
4 vs. 4 & $-0.167^{* * *}$ & $0.172^{* * *}$ \\
All & $-0.344^{* * *}$ & $0.350^{* * *}$ \\
\hline
\end{tabular}

$* * * p<.001$.

\section{Figure 5}

The effect of opponents skill on players changes in skill

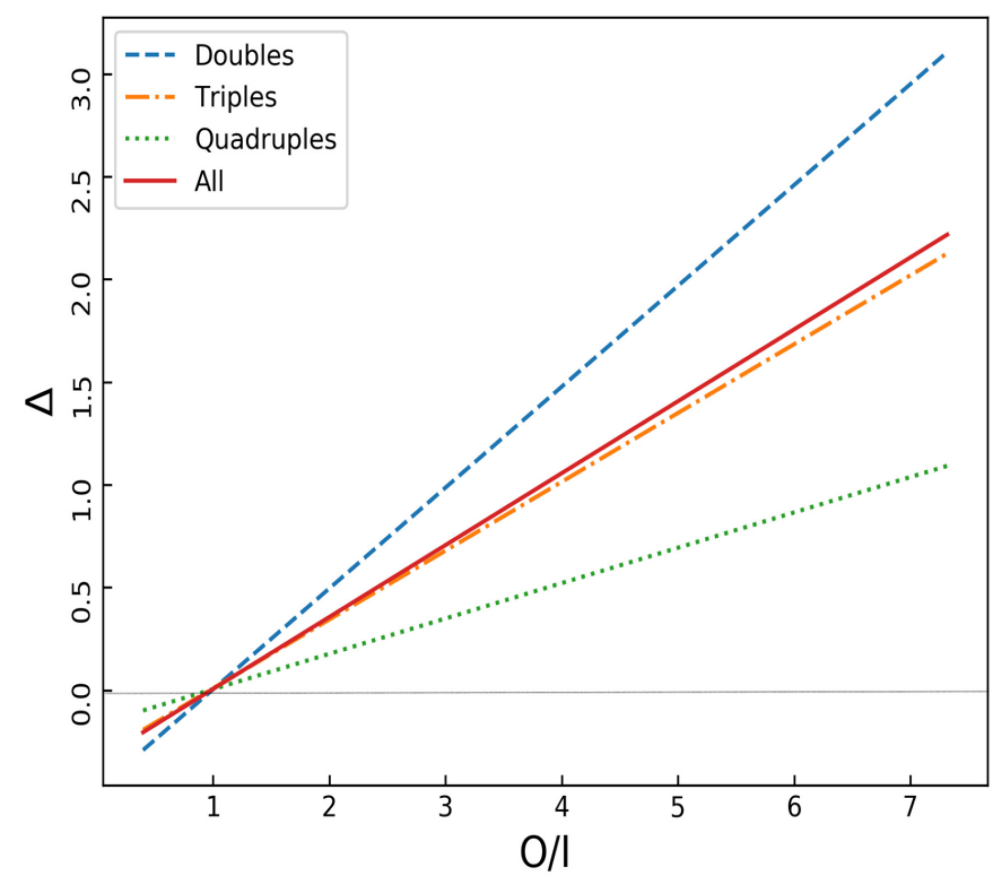

Note. The standard error of all regression slopes is less than 0.001 . 


\section{Figure 6}

Interaction of teammates skill and opponents skill on skill increment

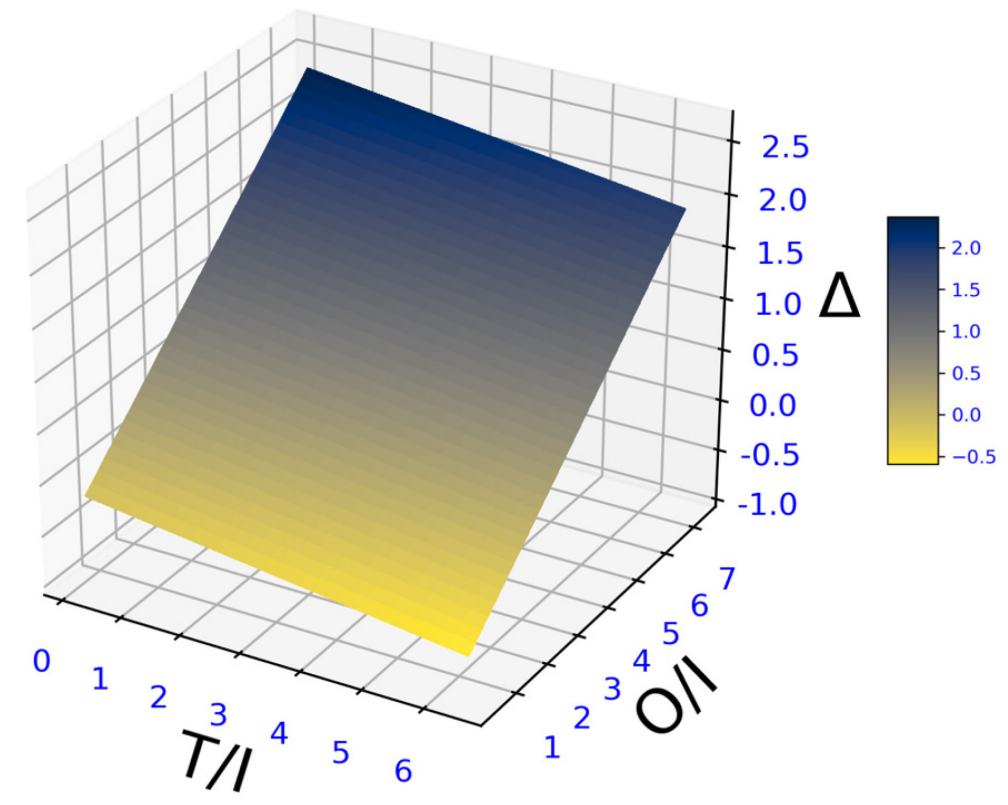

Note. The colour bar from bright yellow to dark blue represents small to large skill

increments. The lower level the teammates and the higher level the opponent, the more the skill increases.

\section{Follow-up Analysis}

Following the preregistration, I have built a nonlinear regression model to try to get more comprehensive findings about RQ2-4. The data is fitted via polynomial regression which fits a nonlinear relationship between predictors and outcome. The departure from the preregistration is identical to that of linear regression analysis: Independent variables are expressed in ratio ( $T / I$ and $O / I)$. The function could be approximated as follows:

$$
f\left(\frac{T}{I}, \frac{O}{I}\right)=\omega+\left(\alpha_{1} \frac{T}{I}+\alpha_{2} \frac{T^{2}}{I}+\cdots+\alpha_{m} \frac{T^{m}}{I}\right)+\left(\beta_{1} \frac{O}{I}+\beta_{2} \frac{O^{2}}{I}+\cdots+\beta_{m} \frac{O^{m}}{I}\right)
$$

The procedure of adding factors to the model is identical to that of linear analysis, except for secondorder polynomials used. Results show that across team games, deviance explained by the model including any factors is almost the same as that of the linear model (see Appendix 1), indicating that there might be no extra benefit to fit data with a nonlinear model. Therefore, contrary to the assumption, in this study it might be unnecessary to fit data with nonlinear regression. 


\section{Discussion}

In this pilot study, how skill acquisition is affected by themselves and peers has been studied in a particular online game. For the influence of initial skill, this study has found that as skill level increases, skill improvements of players become first smaller and then larger. Interacting with higher level opponents is beneficial to individual skill development. In contrast, results fail to highlight the influence of teammates' skill levels on individual skill acquisition. Consequently, this study is unable to support that individual learning rate would be moderated by joint influence of teammates and opponents skill.

\section{Influence of skill level of individual themselves}

Previous research has demonstrated that practice is convincingly predictive to skill acquisition (e.g., Ericsson, Krampe, \& Tesch-Römer, 1993). In a meta-analysis of Macnamara, Hambrick and Oswald (2014), deliberate practice was found to explain $26 \%$ of the deviance in performance for games and $18 \%$ for sports. It is widely held that an individual's skill improves with practice and the corresponding increment is at a decreasing rate. Accordingly, practice can be regarded as a persuasive factor to the skill increment; practice negatively relates to the skill increment. Conversely, there is no evidence supporting that an individual's own skill could be considered as a powerful factor to their skill increment, even though practice is predictive of skill. Correspondingly, in this study, the correlation between individuals' skill and subsequent skill increment is significant but weak $(r=-0.20, p<0.001)$, and the skill level of players themselves only account for a small amount of variance (3.07\%) of their skill increment. A possible explanation for this might be that other factors, except for practice, significantly affect individuals' skill, which further influence their skill development.

As for the trend of skill development, it is somewhat counterintuitive. As shown in Figure 3, the pattern of the first half of the line indicates that skill improvement is at a decreasing rate, but when individual skill level is beyond around 35, the skill improvement turns to be at an increasing rate. The increasing rate is especially evident after skill level of around 40. It is worth noting that the mean skill of all players is 30.18 and there are much fewer data points representing skill levels of 40 and beyond (cf. Figure 3A). Hence, it could be inferred that speedup of players who reach at elite level proceeds at an increasing rate. This is inconsistent with the hypothesis, which is inferred from the law of practice, that skill increment decreases as players improve their skill. The present findings may corroborate the fact of the complexity of learning; there 
are not only stable tendencies but also variabilities in human behaviours (Roediger, 2008). In this sense, there may be exceptions in learning. The great re-improvement perhaps is due to that players gain new much better insights which help them become experts. In light of the result, a widely researched topic not discussed here could be linked, which is to understand how humans reach elite levels of skill, and behavioural and psychological patterns of these experts.

The other striking observation to emerge from the data comparison is the difference of results between three teams. The downward-upward trend of improvements is stable across the team games, but the slope of the trend becomes smaller as the number of players becomes larger. This implies that when more players are included in a match, changes in skill of individual players are smaller. It should be noted that there might be some relations between the number of players and skill acquisition, but whether a causal relationship between them needs more evidence.

\section{Influence of skill level of teammates}

Disappointingly, the current results have not uncovered the influence of teammates skill level on changes in skill. Contrary to the expectation, their correlation is very weak $(r=0.04, p<0.001)$ and T/l accounts for little of variance $(0.24 \%)$ of outcome. This might be owing to characteristics of the data used. As was mentioned in the analysis section, most of the ratio of averaged teammates skill level to individual skill level slightly fluctuates around 1. And if outliers of T/I (data points that fall below Q1-1.5*IQR or above Q3+1.5* IQR, IQR stands for interquartile range) would have been deleted, it would be known that range of $\mathrm{T} / \mathrm{l}$ is too small (from 0.839 to 1.162 ). As such, it is impossible to know the meaningful correlation between variables of interest.

In addition, the ratio indicates that most players and their teammates have similar skill. Although there are no skill matching mechanisms in Conquer Club, ratings rated by other players are publicly viewable. There are three rating attributes of an overall rating and players can use these ratings to decide which game to join: Fair play covers breaking or respecting alliances, chivalry, etc. Gameplay covers diplomacy, teamwork, etc. Attitude covers abusive language, gracious winners, etc. It seems possible that players tend to team up with players with particular ratings which coincidentally may reflect similar skill level. In future investigations, 
it might be possible to focus on the correlation between attributes of behaviours mentioned above and players' skill.

\section{Influence of skill level of opponents}

Relatively speaking, results related to the influence of skill level of opponents are encouraging. Results suggest that playing with higher level opponents has a positive effect on skill increments of players. Inconsistent with the hypothesis that a slightly higher level of opponent is best for a player's skill development, the present results indicate that the higher the level of opponents than the individual, the more the individual improves. When individuals' skill level is higher than that of their opponents, their changes in skill are even negative. The results might be due to the following reasons: Games on Conquer Club have two round length - casual games with 24 hour round and speed games with several minutes. Since most games are casual games ${ }^{2}$, players could play at a relaxed pace, which is as opposed to desirable difficulties. Besides, players could choose to play in sequence or simultaneously. In a sequential game, players have more time to observe opponents' behaviours and imitate their strategies. This study should have taken these variables into account.

Additionally, it is apparent from Figure 5 that fewer players involved in a competition, more skill increments an individual obtains. This phenomenon is similar to that of the influence of the skill level of individuals themselves. Future research could consider the correlation of number of players and changes in skill. Given that the skill ratio of $\mathrm{O} / \mathrm{I}$ ranges from 0.40 to 7.33 , the aforementioned benefits therefore need to be interpreted with caution.

And if outliers of $\mathrm{O} / \mathrm{I}$ would have been deleted, $\mathrm{O} / \mathrm{I}$ would range from 0.454 to 2.118 . This implies that compared to teammate selection, there might be more diversity in opponent selection instead of the preference of similar players. It is likely that three attributes are weighted differently in teammate and opponent selection; all attributes might be taken into account when selecting teammates, while the rating of attitude might be more important in opponent selection. Again, it is merely an assumption and more

\footnotetext{
${ }^{2}$ See https://www.conquerclub.com/public.php?mode=instructions3
} 
studies related to these attributes and skill acquisition should be considered. It is interesting to know what other aspects do players care about their opponents and teammates beyond skill when joining a game.

\section{Joint influence of skill level of teammates and opponents}

The beneficial effects of combining teammates skill and opponents skill in order to account for players' changes in skill is not significant in their interaction. A note of caution is due here since $\mathrm{T} / \mathrm{I}$ alone has no contribution to the model, the interaction of $\mathrm{T} / \mathrm{I}$ and $\mathrm{O} / \mathrm{I}$ could hardly provide additional effects. As noted earlier, the findings may be somewhat limited by data itself, that is, players may have a tendency to collaborate with others of similar level. Consequently, the current study is unable to answer the question whether players' changes in skill would be jointly influenced by skill levels of teammates and opponents.

\section{Implications}

The effect of higher level opponents has implications for practicing strategies. Nowadays, some video games (e.g., Destiny) have automatic skill matching mechanisms based on similar probability of winning of players to enhance their engagement (Graepel \& Herbrich, 2006). As for players themselves, they would like to battle with similar quality of opposition to have better gaming experience and a fair possibility of winning at the same time. But it is not clear if such matching is best for their skill improvement. This study suggests that if one wants to accelerate skill acquisition, higher quality opposition might be a better choice. Whether this strategy could be applied in other domains such as sports is uncertain, more studies focusing on opponent selection are needed. Moreover, the emergence of coaching tools (e.g., the ping pong robot FORPHEUS designed by $\mathrm{OMRON}^{3}$ ) also calls for research to investigate patterns of play to understand strategies facilitating skill learning.

\section{Limitations}

The most important limitation lies in the fact that skill of players and their teammates is about the same level, which limits the investigation of whether players' changes in skill will be influenced by a more broad skill range of teammates. Secondly, this study did not take into account skill disparity within a team.

\footnotetext{
${ }^{3}$ See https://www.omron.com/global/en/technology/information/forpheus/index.html
} 
For example, team A with skill of 15, 9, 9 which is more homogenous than team B with skill of 15, 16, 2 . Previous studies have investigated the relationship between team performance and diversity of culture, nationality, gender, etc. (e.g., Hamilton, Nickerson, \& Owan, 2003; Prat, 2002). In particular, Parshakov, Coates and Zavertiaeva (2018) found that diversity of skill negatively affected performance in eSports. Franck and Nüesch (2010) found different effects of heterogeneity in skill to team productivity at different team levels in sports context. There is still uncertainty, however, whether diversity of skill moderates individuallevel skill learning. The calculation used in this study (i.e. ratio of teammates average skill to individual skill) could only compare the difference between teammates and individual but not among all players in a team. Including a vector of diversity indicators in the model through calculating standard deviation of skill may address this limitation. In spite of these limitations, this pilot study certainly adds to our understanding of the impact of opponents skill level on individual player learning rate.

\section{Future directions}

The present findings provide the following insights for future research: A natural progression of this work is to analyse the teammate's influence using different data of truly randomly matched players. Further, based on that data, the analysis of interaction between skill levels of teammates and opponents could be repeated. More broadly, more studies involving video games and sports are needed to determine the effects of skill levels of teammates and opponents to skill development of a practitioner. Lastly, as mentioned in the second paragraph of this section, identification of significant factors influencing skill acquisition would shed more light on the questions of interest in this study.

Concluding, the insights gained from this study may be of assistance to understand how players' changes in skill are influenced by their own skill levels or that of their opponents in the context of video games. 


\section{References}

Abdelkhalek, N., Hussein, A., Gibbs, T., \& Hamdy, H. (2010). Using team-based learning to prepare medical students for future problem-based learning. Medical Teacher, 32(2), 123-129. https://doi.org/10.3109/01421590903548539

BECKER, T. E., \& KLIMOSKI, R. J. (1989). A FIELD STUDY OF THE RELATIONSHIP BETWEEN THE ORGANIZATIONAL FEEDBACK ENVIRONMENT AND PERFORMANCE. Personnel Psychology, 42(2), 343-358. https://doi.org/10.1111/j.1744-6570.1989.tb00662.x

Bell, S. T. (2007). Deep-level composition variables as predictors of team performance: A meta-analysis. Journal of Applied Psychology, 92(3), 595-615. https://doi.org/10.1037/0021-9010.92.3.595

Bell, S. T., Villado, A. J., Lukasik, M. A., Belau, L., \& Briggs, A. L. (2011). Getting Specific about Demographic Diversity Variable and Team Performance Relationships: A Meta-Analysis. Journal of Management, 37(3), 709-743. https://doi.org/10.1177/0149206310365001

Bjork, R. A. (1994). Memory and metamemory considerations in the training of human beings. In J. Metcalfe and A. Shimamura (Eds.), Metacognition: Knowing about knowing (pp.185-205). Cambridge, MA: MIT Press.

Brown, J. (2011). Quitters Never Win: The (Adverse) Incentive Effects of Competing with Superstars. Journal of Political Economy, 119(5), 982-1013. https://doi.org/10.1086/663306

Brug, J., Kremers, S. P., Lenthe, F. van, Ball, K., \& Crawford, D. (2008). Environmental determinants of healthy eating: in need of theory and evidence. Proceedings of the Nutrition Society, 67(3), 307316. https://doi.org/10.1017/S0029665108008616

Bursztyn, Leonardo; Ederer, Florian; Ferman, Bruno; Yuchtman, N. (2014). Understanding Mechanisms Underlying Peer Effects: Evidence From a Field Experiment on Financial Decisions. Econometrica, 82(4), 1273-1301. https://doi.org/10.3982/ECTA11991

Carrell, S.E.; Sacerdote, B.I.; West, J. E. (2013). From Natural Variation to Optimal Policy? The Importance of Endogenous Peer Group Formation. Econometrica, 81(3), 855-882. 
Carron, A. V., Colman, M. M., Wheeler, J., \& Stevens, D. (2002). Cohesion and performance in sport: A meta analysis. Journal of sport and exercise psychology, 24(2), 168-188.

Chen, G., Kirkman, B. L., Kanfer, R., Allen, D., \& Rosen, B. (2007). A multilevel study of leadership, empowerment, and performance in teams. Journal of Applied Psychology, 92(2), 331-346. https://doi.org/10.1037/0021-9010.92.2.331

de Bruijn, G.-J., Kremers, S. P. J., de Vries, H., van Mechelen, W., \& Brug, J. (2006). Associations of socialenvironmental and individual-level factors with adolescent soft drink consumption: results from the SMILE study. Health Education Research, 22(2), 227-237. https://doi.org/10.1093/her/cyl066

Epple, D., \& Romano, R. E. (2011). Peer Effects in Education. In Handbook of social economics (pp. 10531163). https://doi.org/10.1016/B978-0-444-53707-2.00003-7

Ericsson, K. A., Krampe, R. T., \& Tesch-Römer, C. (1993). The role of deliberate practice in the acquisition of expert performance. Psychological review, 100(3), 363.

Evans, N. J., Brown, S. D., Mewhort, D. J. K., \& Heathcote, A. (2018). Refining the law of practice. Psychological Review, 125(4), 592-605. https://doi.org/10.1037/rev0000105

Falk, A., \& Ichino, A. (2006). Clean Evidence on Peer Effects. Journal of Labor Economics, 24(1), 39-57. https://doi.org/10.1086/497818

Folgado, H., Duarte, R., Fernandes, O., \& Sampaio, J. (2014). Competing with Lower Level Opponents Decreases Intra-Team Movement Synchronization and Time-Motion Demands during Pre-Season Soccer Matches. PLoS ONE, 9(5), e97145. https://doi.org/10.1371/journal.pone.0097145

Franck, E., \& Nüesch, S. (2010). The effect of talent disparity on team productivity in soccer. Journal of Economic Psychology, 31(2), 218-229. https://doi.org/10.1016/j.joep.2009.12.003

Graepel, T., \& Herbrich, R. (2006). Ranking and matchmaking. Game Developer Magazine, 25, 34.

Guillaume, Y. R. F., Brodbeck, F. C., \& Riketta, M. (2012). Surface- and deep-level dissimilarity effects on social integration and individual effectiveness related outcomes in work groups: A meta-analytic integration. Journal of Occupational and Organizational Psychology, 85(1), 80-115.

https://doi.org/10.1111/j.2044-8325.2010.02005.x 
Gula, B., Vaci, N., Alexandrowicz, R. W., \& Bilalic, M. (2020, June 1). Never Too Much - The Benefit of Talent to Team Performance in the NBA: Comment on Swaab et al. (2014). https://doi.org/10.31234/osf.io/hcqaw

Hamilton, B. H., Nickerson, J. A., \& Owan, H. (2003). Team Incentives and Worker Heterogeneity: An Empirical Analysis of the Impact of Teams on Productivity and Participation. Journal of Political Economy, 111(3), 465-497. https://doi.org/10.1086/374182

Hampel, F. R., Ronchetti, E. M., Rousseeuw, P. J., \& Stahel, W. A. (1986). Robust Statistics: The Approach based on Influence Functions. Wiley-Interscience; New York.

Hanushek, E. A., Kain, J. F., Markman, J. M., \& Rivkin, S. G. (2003). Does peer ability affect student achievement? Journal of Applied Econometrics, 18(5), 527-544. https://doi.org/10.1002/jae.741

Heathcote, A., Brown, S., \& Mewhort, D. J. K. (2000). The power law repealed: The case for an exponential law of practice. Psychonomic Bulletin \& Review, 7(2), 185-207.

\section{https://doi.org/10.3758/BF03212979}

Herbrich, R., Minka, T., \& Graepel, T. (2007). TrueSkill ${ }^{\mathrm{TM}}$ : a Bayesian skill rating system. In Advances in neural information processing systems (pp. 569-576).

Hinds, P. J., Carley, K. M., Krackhardt, D., \& Wholey, D. (2000). Choosing Work Group Members: Balancing Similarity, Competence, and Familiarity. Organizational Behavior and Human Decision Processes, 81(2), 226-251. https://doi.org/10.1006/obhd.1999.2875

Huber, P. J. (1964). Robust Estimation of a Location Parameter. Ann. Math. Statist., 35, 73-101.

Jane, W.-J. (2015). Peer Effects and Individual Performance. Journal of Sports Economics, 16(5), 531-539. https://doi.org/10.1177/1527002514521429

Landfried, G., Fernández Slezak, D., \& Mocskos, E. (2019). Faithfulness-boost effect: Loyal teammate selection correlates with skill acquisition improvement in online games. PLOS ONE, 14(3), e0211014. https://doi.org/10.1371/journal.pone.0211014

Li, T., Han, L., Zhang, L., \& Rozelle, S. (2014). Encouraging classroom peer interactions: Evidence from Chinese migrant schools. Journal of Public Economics, 111, 29-45.

https://doi.org/10.1016/j.jpubeco.2013.12.014 
Macnamara, B. N., Hambrick, D. Z., \& Oswald, F. L. (2014). Deliberate Practice and Performance in Music, Games, Sports, Education, and Professions: A Meta-Analysis. Psychological Science, 25(8), 16081618. https://doi.org/10.1177/0956797614535810

Martins, E. C., \& Terblanche, F. (2003). Building organisational culture that stimulates creativity and innovation. European Journal of Innovation Management, 6(1), 64-74. https://doi.org/10.1108/14601060310456337

Mas, A., \& Moretti, E. (2009). Peers at Work. American Economic Review, 99(1), 112-145. https://doi.org/10.1257/aer.99.1.112

Mukherjee, S., Huang, Y., Neidhardt, J., Uzzi, B., \& Contractor, N. (2019). Prior shared success predicts victory in team competitions. Nature Human Behaviour, 3(1), 74-81.

https://doi.org/10.1038/s41562-018-0460-y

Newell, A., \& Rosenbloom, P. S. (1981). Mechanisms of skill acquisition and the law of practice. Cognitive skills and their acquisition, 1(1981), 1-55.

Parshakov, P., Coates, D., \& Zavertiaeva, M. (2018). Is diversity good or bad? Evidence from eSports teams analysis. Applied Economics, 50(47), 5064-5075. https://doi.org/10.1080/00036846.2018.1470315

Prat, A. (2002). Should a team be homogeneous? European Economic Review, 46(7), 1187-1207. https://doi.org/10.1016/S0014-2921(01)00165-9

Rampinini, E., Coutts, A., Castagna, C., Sassi, R., \& Impellizzeri, F. (2007). Variation in Top Level Soccer Match Performance. International Journal of Sports Medicine, 28(12), 1018-1024. https://doi.org/10.1055/s-2007-965158

Roediger, III, H. L. (2008). Relativity of Remembering: Why the Laws of Memory Vanished. Annual Review of Psychology, 59(1), 225-254. https://doi.org/10.1146/annurev.psych.57.102904.190139

Stafford, T., \& Dewar, M. (2014). Tracing the Trajectory of Skill Learning With a Very Large Sample of Online Game Players. Psychological Science, 25(2), 511-518. https://doi.org/10.1177/0956797613511466 Swaab, R. I., Schaerer, M., Anicich, E. M., Ronay, R., \& Galinsky, A. D. (2014). The Too-Much-Talent Effect: Team Interdependence Determines When More Talent Is Too Much or Not Enough. Psychological Science, 25(8), 1581-1591. https://doi.org/10.1177/0956797614537280 
Triplett, N. (1898). The Dynamogenic Factors in Pacemaking and Competition. The American Journal of Psychology, 9(4), 507. https://doi.org/10.2307/1412188

Zimmer, R. W., \& Toma, E. F. (2000). Peer effects in private and public schools across countries. Journal of Policy Analysis and Management, 19(1), 75-92. https://doi.org/10.1002/(SICI)15206688(200024)19:1<75::AID-PAM5>3.0.CO;2-W 


\section{Appendix 1}

Second-order polynomial models explaining changes in skill

\begin{tabular}{lcc}
\hline Team game type & Model & Deviance explained (\%) \\
\hline 2 vs. 2 & $\mathrm{~T} / \mathrm{I}$ & 0.70 \\
& $\mathrm{O} / \mathrm{I}$ & 3.84 \\
& $\mathrm{~T} / \mathrm{I}+\mathrm{O} / \mathrm{I}$ & 3.98 \\
3 vs. 3 & $\mathrm{~T} / \mathrm{I}+\mathrm{O} / \mathrm{I}+\mathrm{T} / \mathrm{I}^{*} \mathrm{O} / \mathrm{I}$ & 4.04 \\
& $\mathrm{~T} / \mathrm{I}$ & 0.90 \\
& $\mathrm{O} / \mathrm{I}$ & 4.16 \\
& $\mathrm{~T} / \mathrm{I}+\mathrm{O} / \mathrm{I}$ & 4.26 \\
& $\mathrm{~T} / \mathrm{I}+\mathrm{O} / \mathrm{I}+\mathrm{T} / \mathrm{I}^{*} \mathrm{O} / \mathrm{I}$ & 4.37 \\
$\mathrm{~T} / \mathrm{I}$ & 0.79 \\
$\mathrm{O} / \mathrm{I} .4$ & $\mathrm{~T} / \mathrm{I}+\mathrm{O} / \mathrm{I}$ & 3.19 \\
& $\mathrm{~T} / \mathrm{I}+\mathrm{O} / \mathrm{I}+\mathrm{T} / \mathrm{I}^{*} \mathrm{O} / \mathrm{I}$ & 3.25 \\
$\mathrm{~T} / \mathrm{I}$ & 3.37 \\
$\mathrm{O} / \mathrm{I}$ & 0.74 \\
& $\mathrm{~T} / \mathrm{I}+\mathrm{O} / \mathrm{I}$ & 3.54 \\
& $\mathrm{~T} / \mathrm{I}+\mathrm{O} / \mathrm{I}+\mathrm{T} / \mathrm{I}^{*} \mathrm{O} / \mathrm{I}$ & 3.64 \\
& & 3.72 \\
\hline
\end{tabular}

